Original Research Article

\title{
Neuroprotective effect of secretin in chronic hypoxia induced neurodegeneration in rats
}

\author{
Gowtham Padmanaban $^{1}$, M. K. Kayalvizhi ${ }^{1}$, Kalyanasundaram Kasiviswanathan ${ }^{2}$, \\ Ruckmani Arunachalam², Vishnu Kumar Urkavalan ${ }^{3}$
}

${ }^{1}$ Department of Pharmacology, Adhiparaskathi Institute of Medical Sciences,

Melmaruvathur, Tamilnadu, India

${ }^{2}$ Department of Pharmacology, Chettinad Hospital and Research Institute, Tamilnadu, India

${ }^{3}$ AMR Pharma Pvt Ltd,

Chennai, Tamil Nadu, India

Received: 22 August 2016

Revised: 01 December 2016

Accepted: 09 December 2016

\section{*Correspondence to:}

Dr. Gowtham Padmanaban, Email:

gowthampharma07@gmail.com

Copyright: (C) the author(s), publisher and licensee Medip Academy. This is an openaccess article distributed under the terms of the Creative Commons Attribution NonCommercial License, which permits unrestricted noncommercial use, distribution, and reproduction in any medium, provided the original work is properly cited.

\begin{abstract}
Background: Hypoxia is a condition in any stage in the delivery of oxygen to cells which include decreased partial pressures of oxygen, less diffusion of oxygen in the lungs, insufficient hemoglobin, inefficient blood flow to the end tissue, and breathing rhythm. Secretin is an amino acid which plays proper functioning of gastro intestinal system.

Methods: The current study was conducted to evaluvate the effect of exogenously administrated secretin on chronic hypoxic damage of brain in rat model. Experimental design consists of control animals, Control animals + secretin hypoxia exposed animals; hypoxia exposed animals +secretin (20ng/kg.bw).
\end{abstract}

Results: The results of this study point to a possible role of Secretin as neuroprotectant.

Conclusions: Further research on secretin needs to be conducted in order to confirm the deductions made by this study.

Keywords: Anti-oxidant, Hypoxia, Secretin, Hemoglobin, Neuroprotectant

\section{INTRODUCTION}

Hypoxia a condition in which the level of oxygen supplied to the body/tissue becomes inadequate. The need for adequate oxygen and glucose supply as well as removal of carbon dioxide is essential for tissue homeostasis. Hypoxia can result from a failure at any stage in the delivery of oxygen to cells which include decreased partial pressures of oxygen, less diffusion of oxygen in the lungs, insufficient hemoglobin, inefficient blood flow to the end tissue, and breathing rhythm. There are four basic causes for hypoxia viz, anoxic hypoxia or diffusion hypoxia, anaemic hypoxia, stagnant hypoxia and histotoxic (histologic) hypoxia.

Hypoxias can occure both acute and chronic. Acute hypoxia is a sudden or rapid depletion in available oxygen at the tissue level. The condition may result from asphyxia, airway obstruction, acute hemorrhage, blockage of alveoli by edema or infectious exudate, or abrupt cardiorespiratory failure. Chronic hypoxia is a 
usually slow, insidious reduction in tissue oxygenation resulting from gradually destructive or fibrotic lung diseases, congenital or acquired heart disorders, or chronic blood loss.

The symptoms of Hypoxia includes, severity and duration like altitude sickness, where hypoxia develops gradually, the symptoms include light-headedness, fatigue, numbness, tingling of extremities, nausea and anorexia. ${ }^{1}$ Severe hypoxia results in ataxia, confusion, disorientation, hallucinations, behavioral change, severe headache, reduced level of consciousness, papilloedema, breathlessness, pallor, tachycardia and pulmonary hypertension, eventually leading to the late signs cyanosis, bradycardia and hypotension followed by death. $^{2,3}$

Secretin is initially synthesized as a 120 amino acid precursor protein known as prosecretin. The mature secretin peptide is a linear peptide hormone, which is composed of 27 amino acids and has a molecular weight of 3055. The amino acids sequences of secretin have some similarities to that of glucagon, vasoactive intestinal peptide (VIP), and gastric inhibitory peptide (GIP). Fourteen of 27 amino acids of secretin reside in the same positions as in glucagon, 7 the same as in VIP, and 10 the same as in GIP. The principle action of secretin is to stimulate bicarbonate secretion to neutralize gastric acid in the duodenum mediated by the secretin receptor, a Gprotein coupled secretin receptor. The receptor is structurally similar to receptors for VIP, glucagon, parathyroid hormone and other Class II G-protein linked receptors. Secretin receptors have been identified by ligand binding and recognition of its mRNA in pancreas, biliary system, stomach, brain and kidney.

Several research works was performed with secretin. When secretin was injected, it decreased the approaches to novel items, movement in an open environment and respiration in rats. Secretin signal plays a neuroprotective role against the neurotoxicity of ethanol induced developmental neurodegeneration in secretin receptordeficient mice. ${ }^{4}$ And some of the research works observed that increased concentrations of glutamate and GABA in rat hippocampus following secretin application. Secretin depressed the effects of single doses of morphine in mice and increased the delay before the animals jumped to avoid an aversive stimulus. ${ }^{5}$ The role secretin in brain metabolism during hypoxia was reported byyungetal. Till a decade ago secretin was known for its gastro intestinal fuctions. But it receptors have been defined and its pleotropic effects outside GIT has been reported by many authors. As secretin has pleiotropic effect, it was planned to study its action in the hypoxia in rats.

\section{METHODS}

Secretin was purchased from Phoenix Pharmaceuticals, USA and all other chemical used were of analytical grade obtained from sisco research laboratory, Mumbai, India. Animal experiments were carriedout after getting clearance from the Institutional Animal Ethical Committee (IAEC No: 06/July 13). The experimental animals were healthy, inbred 20 adult male Wistar albino rats, weighing between 200 - 220g (12 weeks of age) were used. The animals were maintained under standard laboratory conditions and allowed to have food and water. All the rats were housed under conditions of controlled temperature $\left(26 \pm 2{ }^{0} \mathrm{C}\right)$ with $12 \mathrm{hr}$ light and $12 \mathrm{hr}$ dark exposure.

\section{Hypoxic chamber}

Hypoxic chamber consists of an air tight box made up of acriline material in which provision was made for the administration of hypoxic gas. Hypoxic gas was a combination of $92 \%$ nitrogen and $8 \%$ oxygen delivered through a separate cylinder (B type 10.0 litres). Gas cyclinder was purchased from TN oxygen Pvt. Ltd, Ambattur.

\section{Method}

Experimental design consists of Group I- was control animals (normoxia); Group II- Control animals + secretin (20ng/kg.bw); Group III -hypoxia exposed animals; Group IV - hypoxia exposed animals +secretin (20ng/kg.bw). Animals of Group III and Group IV were exposed to hypoxia, by keeping the animals in hypoxic chamber connected to a gas flow of $92 \%$ nitrogen and $8 \%$ oxygen for 45 minutes each day for 14 days. ${ }^{6}$ On the final day of hypoxia exposure, Group II and Group IV were administrated with Secretin intraperitoneally (20 ng/BW) once daily for 3 consecutive days.

\section{Sample collection}

On the $17^{\text {th }}$ day hippocampus was isolated after sacrificing the animals under deep anesthesia using Halothene. Hippocampus was excised, washed in ice cold saline and blotted to dryness. The hippocampus samples were homogenized by using Teflon glass homogenizers. $10 \%$ homogenate hippocampus of tissue was prepared in phosphate buffer (0.1 M, pH 7.0) and centrifuged at 3000 $\mathrm{rpm}$ at $4^{\circ} \mathrm{c}$ for $15 \mathrm{~min}$ to remove cell debris and the clear supernatant was used for further biochemical assays. ${ }^{7}$ The results are expressed as mean \pm standard deviation (SD). All data were analyzed with the SPSS for windows statistical package (version 20.0, SPSS Institute Inc., Cary, North Carolina. Statistical significance between the different groups was determined by one way-analysis of variance (ANOVA). When the groups showed significant difference then Tukey's multiple comparison tests was followed and the significance level was fixed at $\mathrm{p}<0.05$.

\section{Biochemical determinations}

Assay of lipid peroxidation 
Lipid peroxidation (LPO) was determined and the Malondialdehyde (MDA) forms as an intermediate product of the peroxidation of lipids and serves as an index of the intensity of oxidative stress. ${ }^{8}$ MDA reacts with thiobarbituric acid to generate a colored product which absorbs light at $532 \mathrm{~nm}$.

\section{Nitric oxide analysis}

Nitric oxide (NO) levels were measured as total nitrite + nitrate levels by the Griess reagent consists of sulfanilamide and $N$-(1-napthyl)-ethylenediamine. The method is based on a two-step process. ${ }^{9}$ The first step is the conversion of nitrate into nitrite using a nitrate reductase. The second step is the addition of the Griess reagent, which converts nitrite into a deep purple azo compound; photometric measurement of absorbance at $540 \mathrm{~nm}$ is due to the fact that this azochromophore accurately determines nitrite concentration.

\section{Superoxide Dismutase (SOD) assay}

Superoxide dismutase (SOD) was analysed and Pyrogallol auto oxidizes rapidly in an aqueous solution at a fast rate with higher $(\mathrm{pH}=8.0)$ to produce several intermediate products. ${ }^{10}$ The inhibitions of pyrogallol auto oxidation by the enzyme present in sample is employed in the quantification of activity of SOD. The inhibition of auto oxidation brought about by the addition of enzyme, which is evaluated at the early stage as an increase in absorbance at $420 \mathrm{~nm}$ in $0,1,2$ and $3 \mathrm{~min}$ intervals. The unit of enzyme activity is defined as the enzyme required for $50 \%$ inhibition of pyrogallolautooxidation.

\section{Catalase (CAT) assay}

The activity of Catalase (CAT) was analysed, dichromate in acetic acid is reduced to chromic acetate, when heated in the presence of hydrogen peroxide $\left(\mathrm{H}_{2} \mathrm{O}_{2}\right)$ perchloric acid formed as an unstable intermediate. ${ }^{11}$ Since dichromate has no absorbance in this region. The catalase preparation is allowed to split $\mathrm{H}_{2} \mathrm{O}_{2}$ for different period of time and the reaction was arrested by the addition of dichromate/acetic acid mixture at a particular interval of $0,15,30$ and $60 \mathrm{~s}$. The remaining $\mathrm{H}_{2} \mathrm{O}_{2}$ is determined by measuring chromic acetate at $610 \mathrm{~nm}$.

\section{Glutathione peroxidase (GPx) assay}

Glutathione peroxidase (GPx) activity was estimated by tehe reaction between glutathione remaining after the action of GPx and 5, 5'-dithiobis-(2-nitrobenzoic acid) (DTNB) to give a compound that absorbs light at 412 $\mathrm{nm}^{12}$

\section{Estimation of non-enzymatic antioxidants}

Reduced glutathione (GSH) in the hippocampus were estimated by the reaction of GSH with DTNB that gives a compound which absorbs light at $412 \mathrm{~nm}^{13}$

\section{Ascorbic acid (Vitamin- C) assay}

Ascorbic acid was assayed by reacting with copper to form dehydroascorbic acid and diketoglutaric acid, which was then treated with 2,4-dinitrophenyl hydrazine to form the derivative of bis-2,4-dinitrophenyl hydrazine. This compound in sulphuric acid undergoes a rearrangement to form a product which absorbs light at $520 \mathrm{~nm} .^{14}$

\section{RESULTS}

\section{Biochemical assays}

The data are presented with Mean \pm SD in (Figures 1 to 7). There were no significant differences in antioxidant assays between control and secretin control animals. In hypoxia exposed animals LPO, SOD, CAT, Gpx, GSH and Vitamin $\mathrm{C}$ were significantly increased when compared to control and secretin control animal. However hypoxia animals treated with secretin were significantly decreased when compare to hypoxia exposed animals.

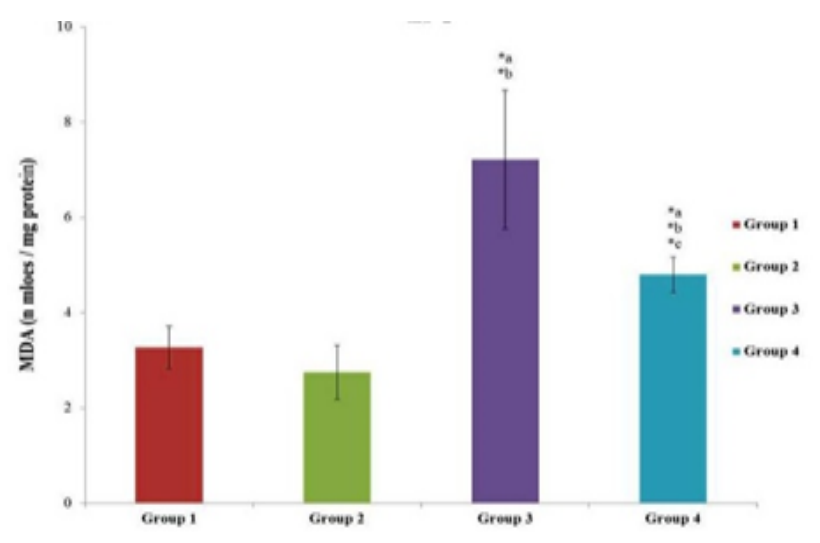

Figure 1: Result of secretin on lipid.

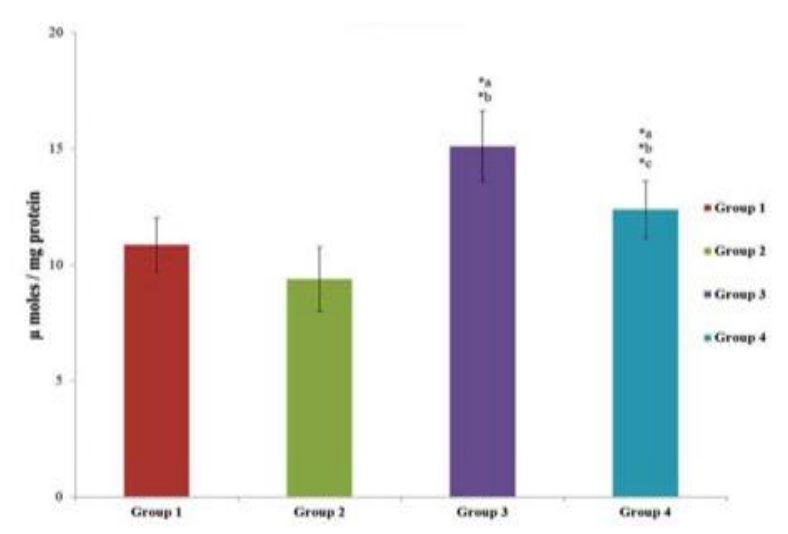

Figure 2: Result of of secretin on Nitric oxide. 


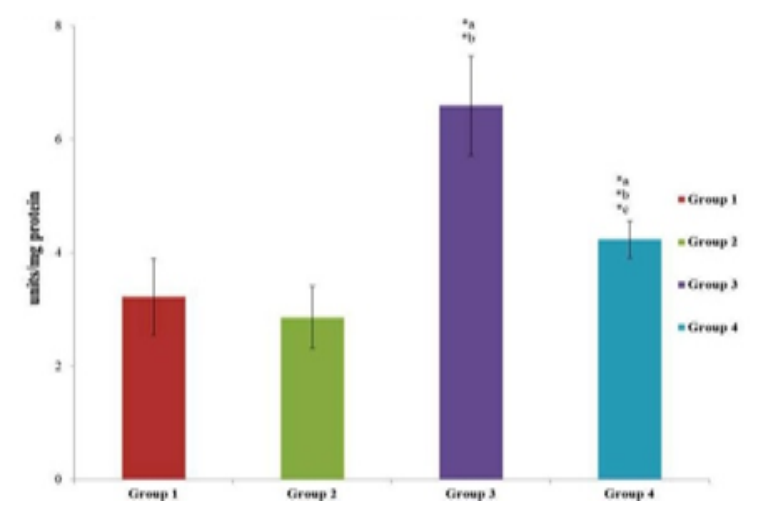

Figure 3: Result of secretin on superoxide dismutase.

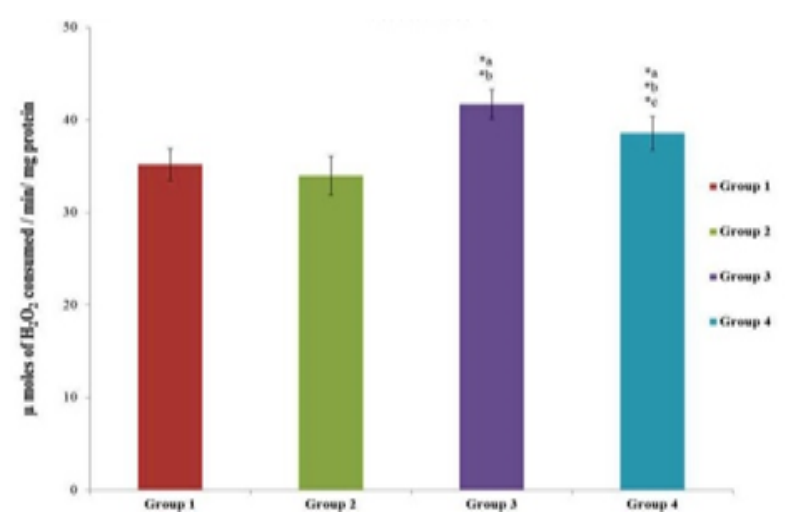

Figure 4: Result of secretin on catalase.

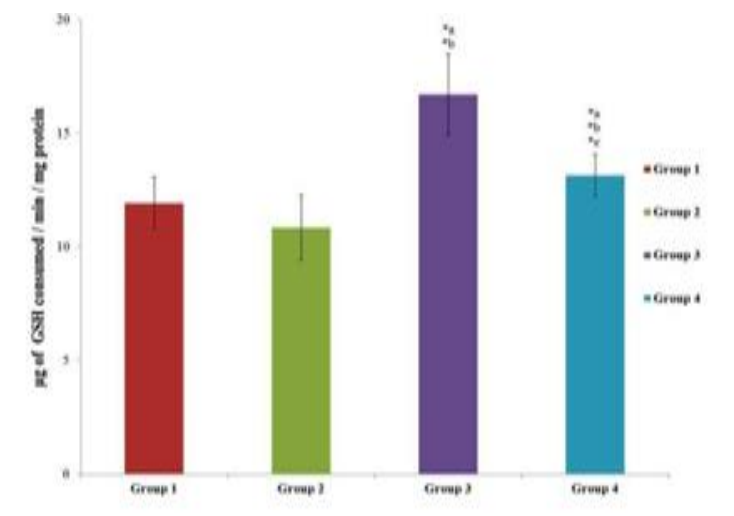

Figure 5: Result of secretin onglutathione peroxidase.

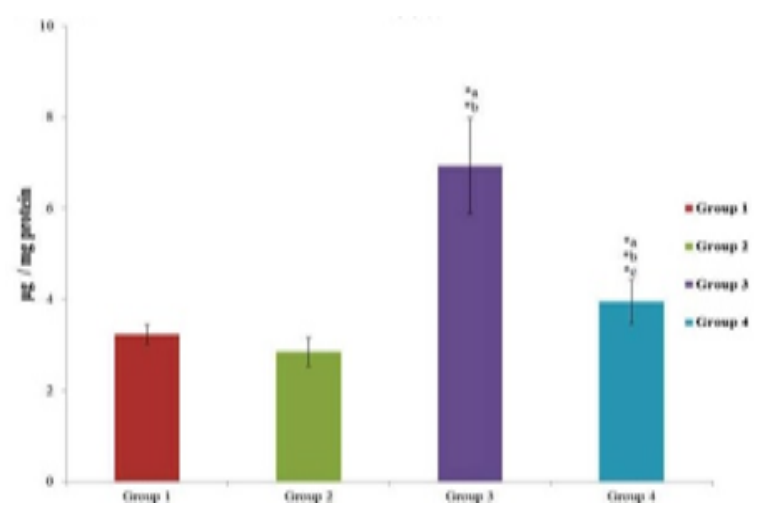

Figure 6: Result of secretin on reduced glutathione.

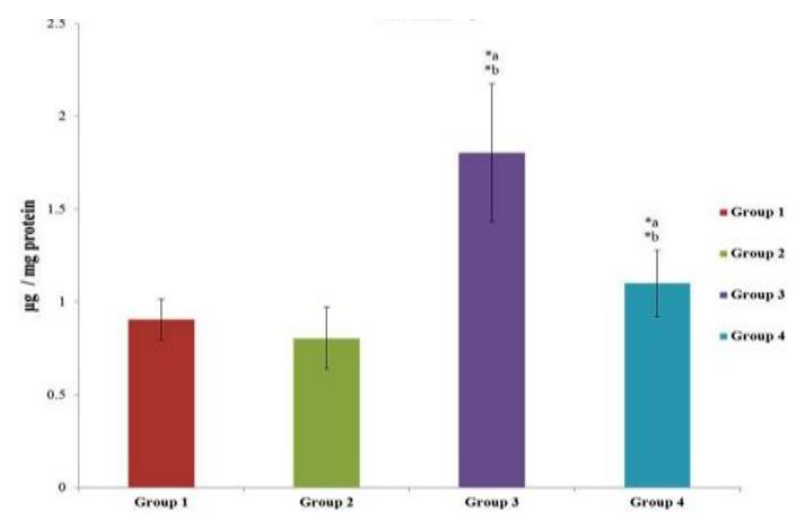

Figure 7: Result of secretin on vitamin-c.

\section{DISCUSSION}

The current study was conducted to evaluate the effect of exogenously administrated secretin on chronic hypoxic damage of brain. Chronic hypoxia resulted in impairing the novelty-seeking behaviour and working memory. Chronic hypoxia produces morphological changes in the hippocampus and causes change in the band appearance of CA 1. These morphological changes may make the hippocampus vulnerable to damage by metabolic challenges, and prolonged oxidative stress can lead to cell death. ${ }^{15,16}$ These chronic hypoxia -induced morphological changes lead to deficits in working memory .The measures of working memory clearly suggest that chronic hypoxia is detrimental to working memory. The experiment reveals a significant induction of lipid peroxidation in the rat brain homogenate of hypoxic groups. Enhanced lipid peroxidation is associated with stimulation of arachidonic acid metabolism and prostaglandin formation. ${ }^{17} \mathrm{~A}$ close association among phospholipid methylation, arachidonic acid release from phospholipid and increased prostaglandin was found. ${ }^{18}$ The protective effects of Secretin on hypoxia induced lipid peroxidation (Figure 7) could be directly attributed to its antioxidant property. As mentioned earlier, hypoxia has been postulated to facilitate the production of arachidonic acid, which could contribute to the oxidative stress in the form of lipid peroxidation. Thus Secretin could be reducing hypoxia - induced increase in arachidonic acid production. Superoxide toxicity appears to be through an indirect action on living cells by giving rise to more powerful oxidants such as the hydroxyl radical. Thedismutation of $\mathrm{O}_{2-}$ generates $\mathrm{H}_{2} \mathrm{O}_{2}$ and oxygen, and this reaction is a spontaneous reaction which can also be catalysed by the enzyme superoxide dismutase. Secretin decreases superoxide dismutase, making cell to clear the free radicals. Hence, superoxide dismutase increases when free radicals increase. In hypoxia treated group superoxide dismutase levels were high compared to other. This shows that hypoxia can elevate free radicals to high level, whereas in hypoxic + secretin treated groups, Superoxide dismutase level is decreased compared to hypoxic group. Hence Secretin acts as an antioxidant by decreasing the free radicals. 
Traumatic injury of the brain is characterised by disruption of cell bodies and axons, followed by little or no axonal regeneration and virtually no recovery of function by the lesioned tissue. These results clearly demonstrate the structural damage that hypoxia causes in the CA1 region of the hippocampus, the part of the brain responsible for learning and memory processing.

The rise in intracellular levels of calcium following hypoxic treatment may be due to either hypoxic stimulating calcium entry or hypoxic inhibiting calcium exit and storage. The increased swelling and necrosis of the cells in the CA1 region may be attributable to increased intracellular levels of calcium as a direct consequence of hypoxia exposure. In hypoxic exposed + secretin treated groups, the cells of CA1 band is slightly disturbed may due to hypoxic stress, but nucleus ,cell membrane are clear. Hence, neurons are normal in spite of hypoxic stress, this may due to protective effect of Secretin. T.

The results of this study point to a possible role of Secretin as neuroprotectant, further research on secretin needs to be conducted in order to confirm the deductions made by this study.

Funding: No funding sources Conflict of interest: None declared

Ethical approval: The study was approved by the Institutional Ethics Committee

\section{REFERENCES}

1. Grac R, Sophie. Oxford Handbook of Respiratory Medicine. Oxford University Press; 2004:880.

2. Illingworth, Robin, Graham, Colin, Hogg, Kerstin. Oxford Handbook of Emergency Medicine. Oxford University Press; 2001:768.

3. Longmore J, Longmore, Murray, Wilkinson, Ian, Rajagopalan, et al. Mini Oxford Handbook of Clinical Medicine; 2006:874.

4. Babarczy E, Szabo G, Telegdy G. Effects of secretin on acute and chronic effects of morphine. Pharmacology, Biochemistry and Behavior. 1995;51:469-72.

5. Chu JY, Yung WH, Chow BK. Ann NY. Secretin. A pleiotrophic hormone. Acad Sci. 2006;1070:27-50.

6. John D. Bancroft, Marilyn Gamble. Histology methods, Theory and practice of Histological Techniques, edition; 2002.
7. Franklin RBJ, Paxinos G. The Mouse Brain in Stereotaxic Coordinates. 1997.

8. Ohkawa H, Ohishi N, Yagi K, Assay for lipid peroxides in animal tissues by thiobarbituric acid reaction, Anal Biochem. 1979;95(2):351-8.

9. Bradford MM. A Rapid and Sensitive Method for the Quantitation of Microgram Quantities of Protein Utilizing the Principle of Protein-Dye Binding, Analytical Biochemistry. 1976;72:248-54.

10. Marklund S, Marklund G. Involvement of the superoxide anion radical in the autoxidation of pyrogallol and a convenient assay for superoxide dismutase, Eur J Biochem. 1974;47(3):469-74.

11. Sinha AK. Colorimetric Assay of Catalase, Analytical Biochemistry. 1972;47(2):389-94.

12. Rotruck JT, Pope AL, Ganther HE, Swanson AB, Hafeman DG, Hoekstra WG. Science. 1973;179:58890.

13. Moron MS, Defierre JW, Mannervik B. Biochem Biophys Acta. 1979;582:67-8.

14. Omaye ST, Turnbull JD, Sauberlich HE. Selected methods for the determination of ascorbic acid in animal cells, tissues and fluids. Methods in Enzymology. 1979;62:3-11.

15. Rauchova M. Vokurkovai Hypoxia-Induced Lipid Peroxidation in the Brain During Postnatal Ontogenesis H. Physiol. 2001;61:S89-101.

16. Brenneman DE. Neuroprotection. A comparative view of vasoactive intestinal peptide and pituitary adenylatecyclase-activating polypeptide. Peptides. 2007;28:1720-6.

17. Bourgault S, Vaudry D, Botia B, Couvineau A, Laburthe M, Vaudry $\mathrm{H}$ et al. Novel stable PACAP analogs with potent activity towards the PAC1 receptor. Peptides. 2008;29:919.

18. Takahashi M, Hasegawa T, Furukawa F, Okamiya H, Shinoda K, Imaida $\mathrm{K}$, et al. Carcinogenesis. 1991;12:2201-4.

19. Crew FT, Morita Y, Hirata F, Axelrod J, Siraganian RP. Biochemical and Biophysics Research Communications. 1980;93:42-9.

Cite this article as: Padmanaban G, Kayalvizhi MK, Kasiviswanathan K, Arunachalam R, Urkavalan VK. Neuroprotective effect of secretin in chronic hypoxia induced neurodegeneration in rats. Int J Basic Clin Pharmacol 2017;6:298-302. 